\title{
Flora da Bahia: Apodanthaceae
}

\author{
Ana Maria Giulietti*, Daniela Santos Carneiro-Torres ${ }^{a}$, Lucas C. Marinho ${ }^{\text {b }}$, Luciano Paganucci de \\ Queiroz $^{\mathfrak{c}}$ \& Reyjane Patricia de Oliveira ${ }^{\mathrm{d}}$
}

Programa de Pós-graduação em Botânica, Departamento de Ciências Biológicas, Universidade Estadual de Feira de Santana, Bahia, Brasil.

\begin{abstract}
Resumo - Duas espécies de Apodanthaceae são reconhecidas na flora do estado da Bahia: Apodanthes caseariae e Pilostyles blanchetii. O tratamento inclui a primeira descrição formal das flores estaminadas de A. caseariae no Brasil, além da discussão sobre as sinonímias e hospedeiros de $P$. blanchetii. São fornecidas chave de identificação, descrições, ilustrações, comentários gerais e um mapa de distribuição das espécies na Bahia.

Palavras-chave adicionais: Apodanthes, Cucurbitales, florística, holoparasita, Pilostyles.
\end{abstract}

\begin{abstract}
Flora of Bahia: Apodanthaceae) - Two species of Apodanthaceae are recognized in the flora of Bahia state, Brazil: Apodanthes caseariae and Pilostyles blanchetii. The taxonomic treatment includes the first formal description of the A. caseariae staminate flowers in Brazil, as well as the discussion on P. blanchetii synonyms and hosts. An identification key, descriptions, illustrations, general notes and a distribution map of species in Bahia are provided.
\end{abstract}

Additional key words: Apodanthes, Cucurbitales, floristics, holoparasite, Pilostyles.

\section{APODANTHACEAE}

Ervas aclorofiladas, endoparasitas de troncos e ramos; porções vegetativas difusas e delicadas, sem caules ou folhas, formadas por sistemas haustoriais filamentosos, apenas as flores emergem do hospedeiro. Flores unissexuadas (plantas dioicas, raramente monoicas) ou raro bissexuadas, actinomorfas, solitárias, distribuídas aleatoriamente ou em grupos ou fileiras no caule e ramos dos hospedeiros; flores estaminadas e pistiladas com 2 ou 3(4) verticilos de tépalas, cada um com (2)3 ou 4(-7) tépalas, livres ou conatas na base, creme, amarelas, alaranjadas ou vináceas, estreitando-se ou alargando-se para a base, margens lisas ou ciliadas; flores estaminadas com coluna central estéril circundada pelos filetes unidos e adnatos à coluna, anteras monotecas arranjadas em 1-4 anéis seguido por anel piloso, ápice da coluna estéril em forma de domo, anteras rimosas, grãos de pólen 3porados; flores pistiladas sem estaminódios, gineceu 4carpelar, gamocarpelar, ovário semi-ínfero, unilocular, pluriovulado, placentação parietal, estigma circular ao redor da coluna, no ápice de um estilete grosso ou séssil. Frutos bagas, irregularmente deiscentes; sementes numerosas, pequenas.

Tradicionalmente, os gêneros hoje reconhecidos em Apodanthaceae eram posicionados entre as Rafflesiaceae, na tribo Apodantheae (Harms 1935; Meijer 1993). Ficaram com posição incerta no APG III

\footnotetext{
*Autora para correspondência: agiuliettiharley@gmail.com;

adscarneiro@hotmail.com; blcmarinho1@gmail.com;

cluciano.paganucci@gmail.com; ${ }^{d}$ rpatricia@uefs.br

Editor responsável: Alessandro Rapini

Submetido: 3 set. 2018; aceito: 10 abr. 2019

Publicação eletrônica: 16 abr. 2019; versão final: 18 abr. 2019
}

(2009) e foram tratados em Cucurbitales no APG IV (2016), seguindo Filipowicz \& Renner (2010). Apodanthaceae reúne endoparasitas de plantas lenhosas, especialmente de Leguminosae e Salicaceae. $\mathrm{Na}$ família, as partes vegetativas são inconspícuas, formadas por células parenquimáticas que se interconectam internamente ao tecido do hospedeiro, denominado sistema endofítico (Solms-Laubach 1901; Endriss 1902; Meijer 1993; Groppo et al. 2007). As flores estaminadas e pistiladas ocorrem em plantas distintas (plantas dioicas) ou raramente na mesma planta (plantas monoicas), mas também podem ocorrer flores bissexuadas (plantas hermafroditas) na família, como observado por Solms-Laubach (1901) em Pilostyles blanchetii (Gardner) R.Br. (como "P. ulei Solms") a partir do material Ule 3094.

As Apodanthaceae estão amplamente distribuídas, embora mal representadas nas coleções de herbário devido à natureza efêmera de seus indivíduos, visíveis apenas durante a floração. A família inclui dois gêneros, o monoespecífico Apodanthes Poit. (Bellot \& Renner 2014) e Pilostyles Guill., com nove espécies, ocorrendo nas Américas do Norte e do Sul, da Califórnia até a Argentina, África continental, sudeste da Ásia e Austrália (Bellot \& Renner 2014). No Brasil, ocorrem os dois gêneros (Groppo 2018), cada qual com uma espécie, ambos representados na Bahia.

\section{Chave para as espécies}

1. Flores com tépalas em 3 verticilos, o externo com 2 tépalas amarelo-fortes, coriáceas, o mediano com 4 tépalas amarelo-claras, cartáceas, e o interno com 4 tépalas creme, membranáceas, todas caducas no fruto ............................. 1.1. Apodanthes caseariae

1 '. Flores com tépalas em 3 verticilos, cada verticilo com 4 tépalas vináceas, as internas às vezes com 
margem ou face adaxial com porções brancas, cartáceas, todas persistentes no fruto 2.1. Pilostyles blanchetii

\section{Apodanthes Poit.}

Flores pistiladas 5-9 mm compr.; tépalas 10, em 3 verticilos, variando quanto à forma, dimensão e textura, as 2 do verticilo externo, coriáceas, amarelofortes, as 4 do verticilo mediano, cartáceas, amareloclaras, e as 4 do verticilo interno, membranáceas, creme, todas caducas no fruto.

Os representantes de Apodanthes são parasitas de troncos e ramos de espécies de Salicaceae (Casearia Jacq. e Xylosma G.Forst.). Vattimo (1971) reconheceu sete espécies em Apodanthes, três delas citadas para o Brasil: A. caseariae Poit., A. minarum Vattimo-Gil. e A. roraimae Vattimo-Gil. Bellot \& Renner (2014), no entanto, consideraram o gênero monoespecífico, aceitando apenas $A$. caseariae e tratando as outras duas espécies acima, juntamente com A. flacoutiae H.Karst. (Venezuela), A. panamensis Vattimo-Gil. (Panamá), A. surinamensis Pulle (Suriname) e A. tribracteata Rusby (Bolívia), em sua sinonímia.

\subsection{Apodanthes caseariae Poit., Ann. Sci. Nat. (Paris)} 3: 422 ; tab. 26. 1824.

Figuras $1 \mathrm{~A}-\mathrm{C}, 2$ e $3 \mathrm{~A}$.

Flores estaminadas globosas, 5,5-6 × 4,5-4,8 mm, distribuídas de forma irregular no tronco da hospedeira; tépalas externas ca. $3 \times 3,5 \mathrm{~mm}$, largoovais, ápice obtuso, margens lisas, tépalas medianas, ca. 2,2 × 1,6 mm, elípticas, ápice arredondado, margens lisas, tépalas internas ca. $3,1 \times 3 \mathrm{~mm}$, obovadas, ápice arredondado, margens lisas; coluna estéril ca. 0,7 mm compr., ápice quase plano; androceu com 2 séries completas de anteras, a superior com 18 anteras e a inferior com 22, com outras 4 anteras maiores abaixo da série inferior, livres entre si. Flores pistiladas distribuídas de forma irregular no tronco da hospedeira, ovoides, 7-9 × ca. $5 \mathrm{~mm}$; tépalas externas $2, \quad 1,5-2,2 \times 2-3 \mathrm{~mm}, \quad$ suborbiculares, ápice arredondado, margens lisas; tépalas medianas 4, 4-6,5 $\times$ 4-4,5 mm, oblongo-ovais, ápice arredondado, margens lisas; tépalas internas 4, 5,5-6,5 × 2,5-3 mm, oblongas, ápice arredondado, margens lisas; ovário ca. $3,5 \times 3 \mathrm{~mm}$, estilete ca. 0,2 mm compr., estigma ca. 0,8 $\times 2 \mathrm{~mm}$. Bagas ovoides, 9-10 × 7,5-8 mm, amarelas ou alaranjadas; sementes mais de 100 por fruto, ca. 0,3 mm compr.

Apodanthes caseariae distribui-se nas Américas Central e do Sul, desde o Panamá, Venezuela, Guianas, Peru e Bolívia até o Brasil (Vattimo 1971; Bellot \& Renner 2014). No Brasil, é referida para as Regiões Norte (Amazonas e Roraima), Nordeste (Bahia), Centro-Oeste (Mato Grosso) e Sudeste (Espírito Santo e Minas Gerais) (Groppo 2018). F8, G7 e G8: Mata Atlântica, em florestas ombrófilas densas. Coletada com flores pistiladas e frutos entre janeiro e agosto e flores estaminadas em janeiro.

Material examinado - Almadina, $6 \mathrm{~km} \mathrm{~W}$ na estrada para Ibitupã, então $7 \mathrm{~km}$ para a comunidade de Sete Paus, $14^{\circ} 42^{\prime} 19^{\prime \prime S}$, 39³8'14"W, 500 m s.n.m., 27 jan. 1999 (fl. đో), W.W. Thomas et al. 11855 (NY); Apuarema, concessão da Rio Tinto, 13²51'23"S, 3944'38"W, 709 m s.n.m., 7 mar. 2013 (fr. jov.), L.Y.S. Aona et al. 2298 (HUEFS, HURB); Boa Nova, Parque Nacional de Boa Nova, $14^{\circ} 21^{\prime} 45^{\prime \prime S}, 40^{\circ} 12^{\prime} 27^{\prime \prime W}, 843$ m s.n.m., 6 jan. 2013 (fl. P), L.Y.S. Aona et al. 1868 (HURB); Uruçuca, distrito de Serra Grande, 14³5'35"S, 39¹7'04"W, 12 ago. 1992 (fr.), A.M. Carvalho et al. 4075 (CEPEC, NY).

Material adicional examinado: BRASIL. MINAS GERAIS: São Miguel do Anta, estrada para a cidade, 31 mar. 1930 (fl. ㅇ), $Y$. Mexia 4540 (K, isótipo de Apodanthes minarum). RORAIMA: arredores de Auaris, 24 set. 1974 (fl. + ), G. Prance 21353 (K, isótipo de Apodanthes roraimae). GUIANA. Wassarai Mount, 00 $33^{\prime} 54^{\prime \prime N}, 59^{\circ} 14^{\prime} 08^{\prime \prime} \mathrm{W}, 9$ set. 1999 (fr.), H.D. Clark et al. 8358 (NY). GUIANA FRANCESA. Karauany, s.d. (fl. + ), P.A. Poitier s/n. ex Herb. Sagot 1158 (K00060131, isótipo de Apodanthes caseariae)

Apodanthes caseariae é conhecida na Bahia por apenas cinco coletas em áreas do domínio da Mata Atlântica, sendo quatro de plantas pistiladas (com flores ou frutos) e apenas uma (Thomas 11855) com botões estaminados, quase em antese. Parasitam troncos e ramos de árvores altas de Casearia (Salicaceae), incluindo C. arborea (Rich.) Urb. (Aona 1868, in sched.). Bellot \& Renner (2014) descreveram frutos com 13-15 mm de comprimento (vs. 9-10 mm compr. nos espécimes da Bahia) e, no espécime da Guiana (Clark 8358), os frutos são ainda maiores (ca. $16,5 \mathrm{~mm}$ compr.). Até aqui, a única referência para flores estaminadas no Brasil havia sido feita com base num exemplar do Mato Grosso, coletado em 1919 (Kuhlmann s.n., herb. R n.v.). Segundo Vattimo (1971), ele seria monoico, com flores estaminadas e pistiladas, porém nenhuma descrição formal foi apresentada com base nesse material. Assim, a primeira descrição formal das flores estaminadas de Apodanthes caseariae no Brasil é feita aqui. Bellot \& Renner (2014) apontaram os espécimes Foster 2354 (herb. PMA), do Panamá, e Callejas 8062 (NY), da Colômbia, como estaminados; no primeiro, as flores medem cerca de $2,5 \mathrm{~mm}$ de comprimento, e no outro, entre 3-4,5 mm. No espécime da Bahia, as flores estaminadas são menores que as pistiladas, medem 5,5-6 mm. Também foi notada pela primeira vez aqui (Thomas 11855), a presença de dois verticilos de anteras em anel perfeito e quatro anteras maiores abaixo do verticilo inferior. Essas anteras eram as únicas abertas, liberando grãos de pólen, indicando que a maturação das anteras ocorre de forma centrípeta. Com base nos espécimes examinados aqui, as sinonimizações propostas por Bellot \& Renner (2014) parecem pertinentes. No entanto, as variações no tamanho das flores e frutos sugerem a necessidade de estudos mais detalhados, especialmente no campo. 


\section{Pilostyles Guill.}

Flores pistiladas com até $5 \mathrm{~mm}$ compr.; tépalas em (2)3 verticilos, o externo com 3 ou 4(5) tépalas, o mediano, quando presente, com 3 ou 4(-6) tépalas, o interno com (3)4(-6) tépalas, mais ou menos com as mesmas formas, dimensões e textura, vináceas, as do verticilo interno às vezes com margens ou face adaxial com porções brancas, cartáceas, persistentes no fruto.

Os representantes de Pilostyles são parasitas de ramos de diversos gêneros de Leguminosae. Vattimo (1971) reconheceu 17 espécies de Pilostyles para as Américas, sendo duas nos Estados Unidos, seis no México e nove na América do Sul, seis delas citadas para o Brasil. Bellot \& Renner (2014), por outro lado, reconheceram apenas nove espécies no gênero, sendo três na Austrália, uma na África, uma no Oriente Médio, duas nos Estados Unidos e México, uma no Chile e Argentina ( $P$. berteroi Guill.) e uma com distribuição neotropical, ocorrendo também na Argentina e Uruguai ( $P$. blanchetii). Todos os representantes americanos de Pilostyles possuem flores com três verticilos, enquanto em duas espécies da Austrália, as tépalas aparecem em dois verticilos, não havendo o verticilo mediano (Bellot \& Renner 2014). No material da Bahia, foram observadas quatro tépalas nos três verticilos florais.

2.1. Pilostyles blanchetii (Gardner) R.Br., Trans. Linn. Soc. London 19(3): 247. 1844 (como "1845").

Figuras 1D-L, 2 e 3B-D.

Flores estaminadas globosas, $2-3 \times 2-3 \mathrm{~mm}$; distribuídas mais ou menos em fileiras ao longo dos ramos do hospedeiro; tépalas externas 4, 1,5-2 × 1,4-2 $\mathrm{mm}$, ovais, ápice arredondado, margens fimbriadas, tépalas medianas $4,1,5-2,3 \times 0,7-2 \mathrm{~mm}$, elípticas, ápice arredondado, margens lisas, tépalas internas 4 , $1,3-1,8 \times 1-1,4 \mathrm{~mm}$, obovais a oboval-arredondadas, ápice arredondado, margens fimbriadas; coluna estéril ca. 0,6 mm compr., ápice arredondado; androceu com 2 séries completas de anteras, cada qual com ca. 12 anteras. Flores pistiladas globosas a subglobosas, dispostas mais ou menos em fileiras ao longo do ramo do hospedeiro; 2,5-3,5 × 2,3-3,5 mm; tépalas externas 4, 2-2 × 1,5-2 mm, ovais, ápice arredondado, margens fimbriadas ou lisas, tépalas medianas $4,2-2,5 \times 1,5-2$ $\mathrm{mm}$, ovais, oval-oblongas ou elípticas, margens fimbriadas, raramente lisas, tépalas internas 4, 1,8-2,5 $\times 1,4-1,7 \mathrm{~mm}$, largo-ovais ou oboval-oblongas, ápice arredondado, margens geralmente fimbriadas; ovário ca. $1,5 \times 1 \mathrm{~mm}$, estilete ca. $0,3 \mathrm{~mm}$ compr., estigma ca. $0,8 \times 1 \mathrm{~mm}$. Bagas subglobosas, $2-3 \times 1,5-1,8 \mathrm{~mm}$, vináceas; sementes mais de 100 por fruto, ca. $0,3 \mathrm{~mm}$ compr.

Pilostyles blanchetii distribui-se na América do Norte [México, com a sinonimização de P. globosa (S.Watson) Hemsl.], América Central (Costa Rica, Ilhas Cayman, Jamaica e Panamá) e América do Sul (Argentina, Brasil, Colômbia, Guiana, Suriname, Uruguai e Venezuela) (Bellot \& Renner 2014). No
Brasil, é referida para as Regiões Norte (Pará e Roraima), Nordeste (Bahia e Pernambuco), CentroOeste (Goiás), Sudeste (Minas Gerais e São Paulo) e Sul (Paraná e Santa Catarina) (Groppo 2018). B5/6, D3, D6, E2/3, E8, F6, F8, G3, G5, G8, H8: domínios fitogeográficos da Caatinga e do Cerrado, incluindo vegetação de campo rupestre. Coletada com flores estaminadas e pistiladas de janeiro a abril e de setembro a novembro.

Material selecionado - Abaíra, Bem Querer, $13^{\circ} 16^{\prime} \mathrm{S}$, 415' W, 1330 m s.n.m., 4 mar. 1992 (fl. §)), B. Stannard et al. H51762 (HUEFS, NY, USP); Barreiras, cerca de $4 \mathrm{~km}$ na estrada para o aeroporto, $12^{\circ} 09^{\prime} 10^{\prime \prime S}, 44^{\circ} 59^{\prime} 24^{\prime \prime} \mathrm{W}, 750 \mathrm{~m}$ s.n.m., 19 abr. 2009 (bot.), L.P. Queiroz 13969 (HUEFS); Caetité, Brejinho das Ametistas, $14^{\circ} 15^{\prime} 37^{\prime \prime} \mathrm{S}, 42^{\circ} 31^{\prime} 27^{\prime \prime} \mathrm{W}, 900-1000 \mathrm{~m}$ s.n.m., 8 mar. 1994 (fl. §)), N. Roque et al. CFCR 14953 (ESALQ, K, NY, UEC, USP); Cocos, cerca de $5 \mathrm{~km}$ da cidade, Espigão Mestre, $530 \mathrm{~m}$ s.n.m., 17 mar. 1972 (fl. +), W.R. Anderson et al. 37104 (NY); Feira de Santana, distrito de Ipuaçu, $12^{\circ} 13^{\prime} 58^{\prime \prime} \mathrm{S}, 39^{\circ} 04^{\prime} 36^{\prime \prime} \mathrm{W}$, 200-300 m s.n.m., 9 nov. 2004 (fl. đ̊), S.F. Conceição 83 (HUEFS); Iaçu, Morro do Coité, 1245'18"S, 3953'57"W, 278 m s.n.m., 28 set. 1997 (fl. §̊), E. Melo et al. 2273 (HUEFS); Ibirataia, entre os povoados de Mineiros e Algodão, $14^{\circ} 04^{\prime} 01^{\prime \prime S}, 39^{\circ} 38^{\prime} 26^{\prime \prime} \mathrm{W}, 715 \mathrm{~m}$ s.n.m., 22 jul. 2013 (fl.), L.Y.S. Aona 2898 (HURB); Itaberaba, Serra do Orobó, $11^{\circ} 19^{\prime} 35^{\prime \prime}$ S, 44¹1'31"W, 700 m s.n.m., 13 mar. 1999 (fl. ㅇ), R.M. Harley et al. 53495 (HUEFS); Itatim, Fonte Monte Alto Francisco Felix, $12^{\circ} 45^{\prime} \mathrm{S}, 39^{\circ} 42^{\prime} \mathrm{O}, 420 \mathrm{~m}$ s.n.m., 16 nov. 2012 (fl. ㅇ), E. Melo et al. 11792 (HUEFS); Jussari, RPPN Serra do Teimoso, $15^{\circ} 09^{\prime} 29^{\prime \prime S}, 39^{\circ} 31^{\prime} 43^{\prime \prime W}$, s.d. (fl. §), A.M. Amorim et al. 2898 (CEPEC, NY); Morro do Chapéu, Serra do

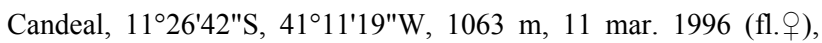
A.M. Giulietti et al. PCD2280 (ALCB, HUEFS, USP); Piatã, encosta da Serra do Barbado, $13^{\circ} 17^{\prime}$ 'S $41^{\circ} 54^{\prime}$ W, 1719 m s.n.m., 6 set. 1996 (fl. ㅇ), R.M. Harley et al. 28328 (HUEFS); Remanso, Serra do Piauí, 09³7'18"S, 4204'53"W, jan. 1907 (fl. ㅇ), E. Ule 7078, 7079 (K); Rio de Contas, Pico das Almas, acima do Campo do Queiroz, 1500 m s.n.m., 15 nov. 1988 (fl. +), R.M. Harley et al. 26163 (HUEFS, K, NY); São Desidério, cerrado próximo ao rio Piauí, ca. 150 km SW de Barreiras, 12²1'48"S, 4458'24"W, $850 \mathrm{~m}$ s.n.m., 15 abr. 1966 (fr.), H.S. Irwin 14911 (NY); São Miguel das Matas, fazenda Engenho da Lama, ca. 4,5 km da cidade, 1302'49"S, 39²5'56"W, 400 m s.n.m., 24 fev. 2000 (fl. §̊), J.G. Jardim 2866 (HUEFS, NY); Sento Sé, cerca de $2 \mathrm{~km}$ na estrada para Mimoso, $09^{\circ} 44^{\prime} 45^{\prime \prime S}, 41^{\circ} 53^{\prime} 07^{\prime \prime W}, 1038$ m s.n.m., 30 jan. 2010 (fl. +), J.R. Maciel 1429 (HVASF); Sem Município, Serra do Açuruá, s.d. (fl. ㅇ), J.S. Blanchet 2861 (holótipo K, isótipos K (2 exs.), MG, NY).

Material adicional examinado: BRASIL. GOIÁS: sapê, fev. 1840 (fl. ㅇ), G. Gardner 3639 (K). PARÁ: Parauapebas, Serra Norte, N1, canga arbustiva, 06 $02^{\prime} 56.5^{\prime \prime} \mathrm{S}, 50^{\circ} 17^{\prime} 06.1^{\prime \prime} \mathrm{W}, 686 \mathrm{~m}$ s.n.m., 20 fev. 2018 (fl. §), W.M. Rangel et al. 1 (MG). PIAUÍ: Serra Branca, jan. 1907 (fl. §), E. Ule 7161 (K, MG). RORAIMA: rio Surumu, tributário do rio Branco, mar. 1910 (fl. ㅇ), E. Ule 7895 (K). ILHAS CAYMAN. Grand Cayman, ao longo da face W da área montanhosa, 2 mar. 1993 (fl. ㅇ, fr), G.R. Proctor \& F. Burton 48666 (NY). MÉXICO. CHIAPAS: set. 1923 (fl. ㅇ), C.A. Purpus 9153 (NY) [P. mexicana (Brandegee) Rose].

Bellot \& Renner (2014) indicaram como hospedeiras de Pilostyles blanchetii as espécies de 

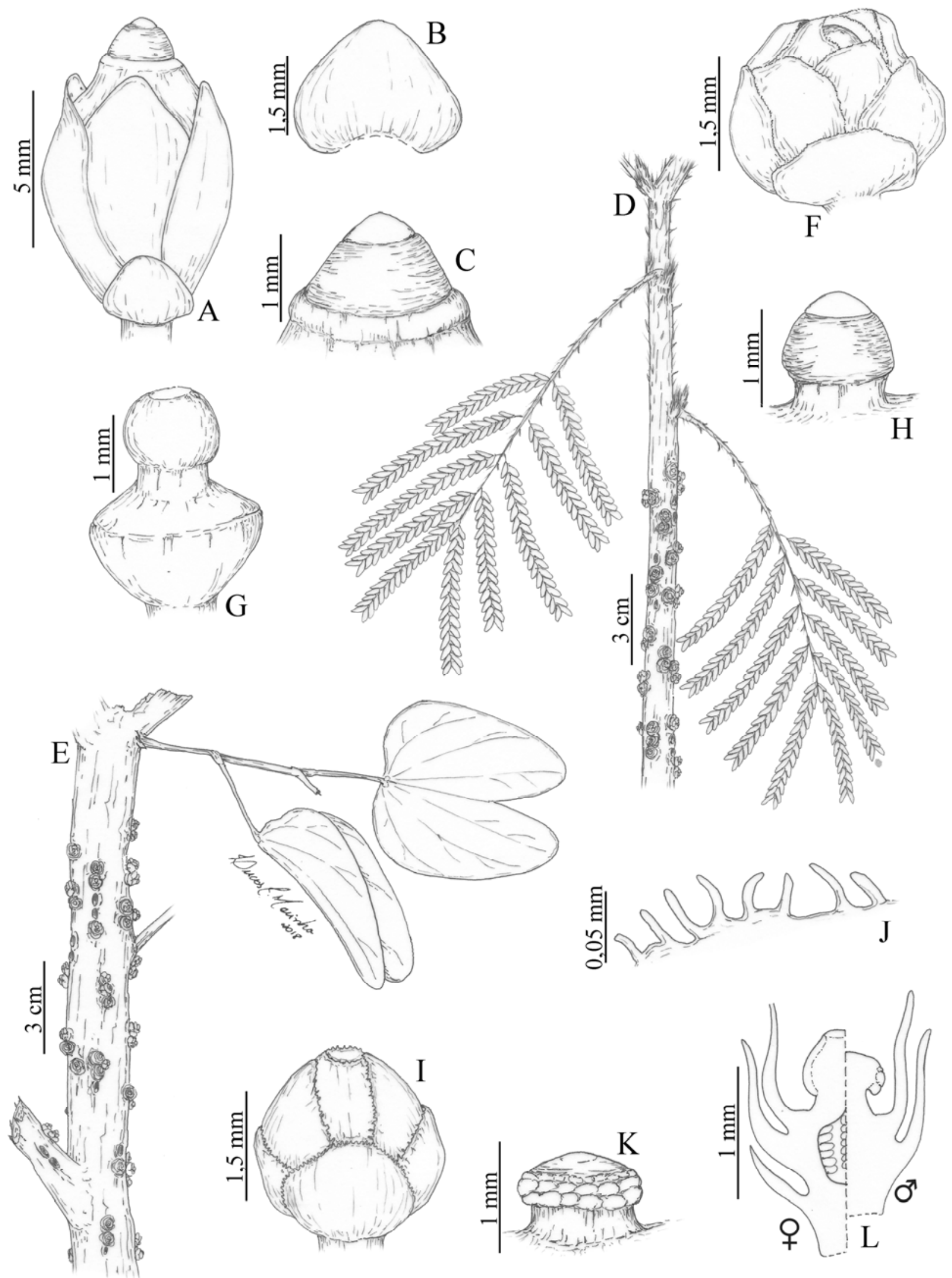

$\mathrm{H}$
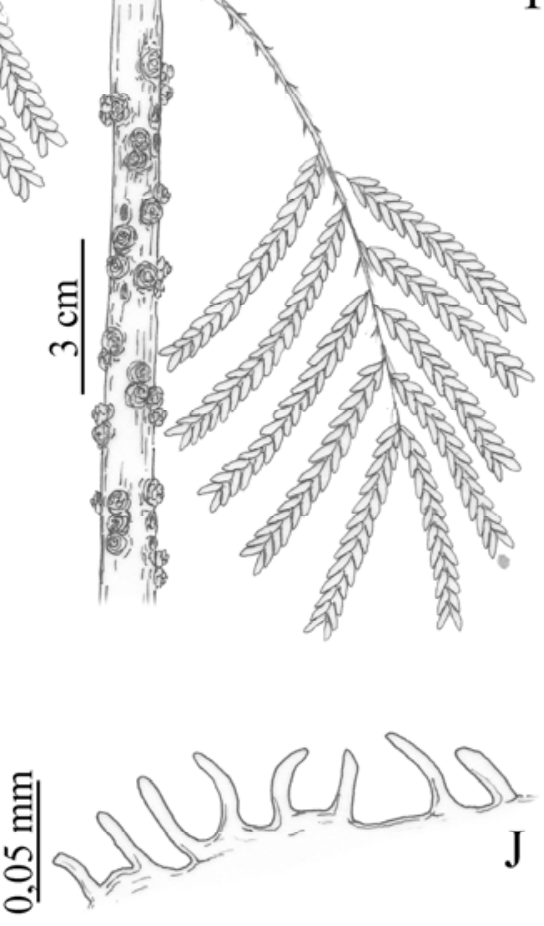

Figura 1. A-C. Apodanthes caseariae: A- fruto jovem; B- tépala externa; C- detalhe da coluna mostrando o ápice estéril e o estigma apical anular. D-L. Pilostyles blanchetii: D- parasitando Bauhinia subclavata (Leguminosae); E- parasitando Mimosa setosa var. paludosa (Leguminosae); F- flor pistilada; G- flor pistilada com perianto removido; H- detalhe da coluna mostrando o ápice estéril e estigma subapical anular; I- flor estaminada; J- detalhe da margem fimbriada das tépalas; K- detalhe da coluna mostrando o ápice estéril e duas séries de estames logo abaixo. L- esquema de corte longitudinal das flores pistilada e estaminada. (A-C- Aona 2298, fr. jov.; D, G, L- Melo 11792, fl. ○; E- Harley 24526, fl. ๆ; F, H- Harley 28328, fl. ㅇ; I-L- Melo 2273, fl. §̊). 


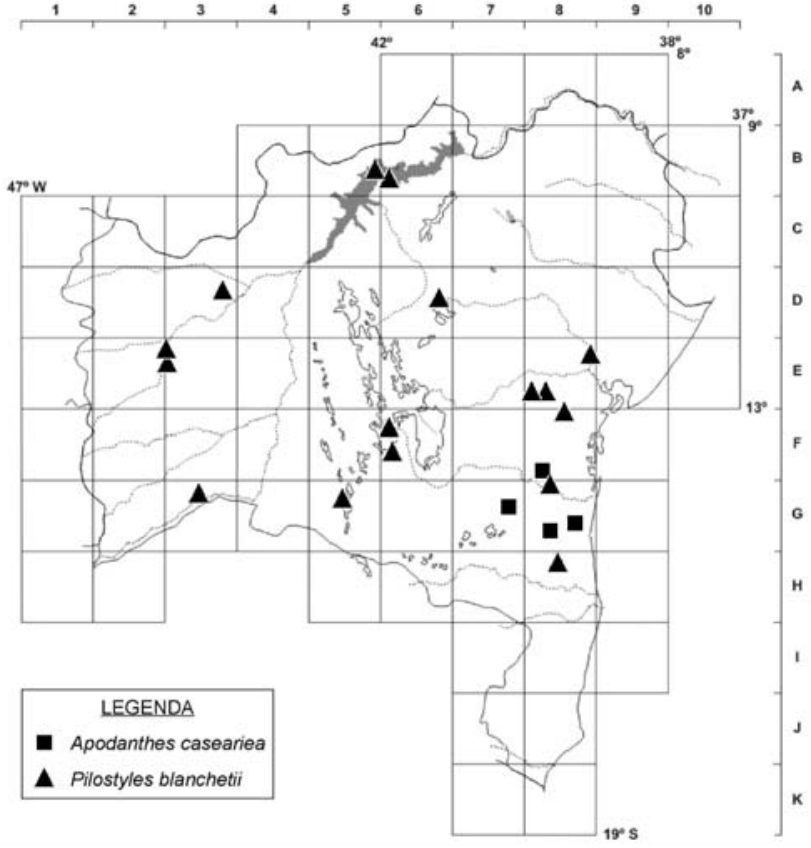

Figura 2. Distribuição geográfica de Apodanthes caseariae e Pilostyles blanchetii no estado da Bahia.

Leguminosae: Bauhinia candicans Benth., B. divaricata L., Mimosa claussenii Benth., M. cyclophylla Taub., M. aff. setosa Benth., M. maguirei Barneby, M. scabrella Benth., M. setosissima Taub., M. uraguensis Hook. \& Arn., M. cf. xanthocentra Mart. e Schnella cumanensis (Kunth) Britton \& Rose. Pilostyles blanchetii é referida também como parasita de espécies não identificadas dos gêneros Dioclea Kunth e Galactia P.Browne (Vattimo 1971; Groppo et al. 2007; Bellot \& Renner 2014). Com base nos espécimes da Bahia, reconhecemos ainda seu parasitismo em Bionia Mart. ex Benth. e Calliandra Benth., além de registrar pela primeira vez o parasitismo em doze outras espécies de Leguminosae: Bauhinia acuruana Moric. (França 5710, Giulietti PCD2280), B. brevipes Vogel (Irwin 31315), B. catingae Harms (França 2329), B. cheilantha (Bong.) Steud (Melo 2273), B. dubia G.Don (Irwin 31345), B. subclavata Benth. (Melo 11792), Bionia coriacea (Nees \& C.Mart.) Benth. (Queiroz 13969), Calliandra leptopoda Benth. (Ule 7079), C. squarrosa Benth. (como "C. catingae Harms"; Ule 7078), Dioclea coriacea Benth. (Irwin 31560), Mimosa setosa var. paludosa (Benth.) Barneby (Harley 24526, 26163, 28328 e Hind 4267) e Schnella trichosepala (L.P.Queiroz) Wunderlin (Harley 53495). A maioria dessas espécies hospedeiras apresentam ampla distribuição no Brasil, nas Regiões Nordeste, Sudeste (geralmente Minas Gerais) e Centro-Oeste (geralmente Goiás e Distrito Federal), algumas alcançando a região Norte, e estão geralmente associadas a áreas sujeitas a climas sazonais em vegetação de caatinga, cerrado e campo rupestre (Flora do Brasil 2020). Pastore et al. (2018) indicaram que as plantas da Serra dos Carajás, no Pará, parasitam Bauhinia pulchella Benth., espécie que ocorre nas Regiões Centro-Oeste, Nordeste, Norte e Sudeste do Brasil; na Bahia, ela é muito frequente ao longo da Chapada Diamantina. Entretanto, a única coleta de $P$. blanchetii parasitando essa espécie foi feita em São Desidério, no oeste do estado. Em relação ao gênero Mimosa, as amostras da Bahia indicam parasitismo apenas em $M$. setosa var. paludosa, que deve corresponder a $M$. aff. setosa referida em Bellot $\&$ Renner (2014). Deve ser destacado que $M$. xanthocentra Mart. apresenta distribuição ampla, ocorrendo também na Bahia, mas não foi encontrada até o momento sendo parasitada por P. blanchetii. Em relação ao gênero Schnella Raddi, registramos o parasitismo de S. trichosepala; S. cumanensis, previamente citada como hospedeira da espécie, não ocorre no Brasil.

A inclusão de espécies de Calliandra como hospedeiras de Pilostyles blanchetii levanta uma importante discussão. Os espécimes Ule 7078 e 7079 foram identificados como P. calliandrae (Gardner) R.Br. e posteriormente como P. mexicana (Brandegee) Rose (S. Bellot 2013, in sched.), com a seguinte observação: "from host and geography, probably $P$. mexicana". Na chave de identificação para as espécies de Apodanthaceae (Bellot \& Renner 2014), P. blanchetii (incluindo P. calliandrae) distingue-se geralmente por possuir as tépalas medianas rômbicas ("diamond shape") e aparentemente nunca parasita Calliandra, enquanto $P$. mexicana possui as tépalas medianas ovais e parasita Calliandra. Pastore et al. (2018) referem que os espécimes examinados da Serra dos Carajás apresentam as tépalas medianas de oblongas a elípticas, assemelhando-se com a descrição de Groppo et al. (2007) para os espécimes da Serra do Cipó, em Minas Gerais. O espécime Proctor \& Burton 48666, de flores pistiladas (parasitando Bauhinia divaricata e identificado como P. blanchetii) apresenta as tépalas medianas ovais, enquanto no espécime Purpus 9153, identificado como P. mexicana, elas são oval-oblongas. A análise dos espécimes da Bahia mostrou variação na forma das tépalas medianas das flores pistiladas, de oval (Anderson 37104) a ovaloblonga (Irwin 31588) ou elíptica (Harley 26163), porém todas as flores estaminadas apresentaram tépalas medianas elípticas (Irwin 31560 e Stannard 51762). Nenhum dos espécimes examinados apresentou tépalas medianas rômbicas; por isso, consideramos os espécimes de Pilostyles da Bahia parasitando Calliandra também como P. blanchetii. Assim, neste tratamento, estamos aceitando as sinonimizações de $P$. calliandrae, $P$. galactiae Ule, $P$. globosa, $P$. goyasensis Ule, P. stawiarskii Vattimo-Gil e P. ulei Solms em Pilostyles blanchetii, posição subsidiada também por evidências moleculares (Bellot \& Renner 2014). Ainda assim, a delimitação de $P$. blanchetii não parece definitiva. São necessários estudos que permitam compreender melhor a influência do hospedeiro na morfologia desses parasitas; só então, a taxonomia de Pilostyles e a circunscrição de suas espécies se tornarão claras e confiáveis. 


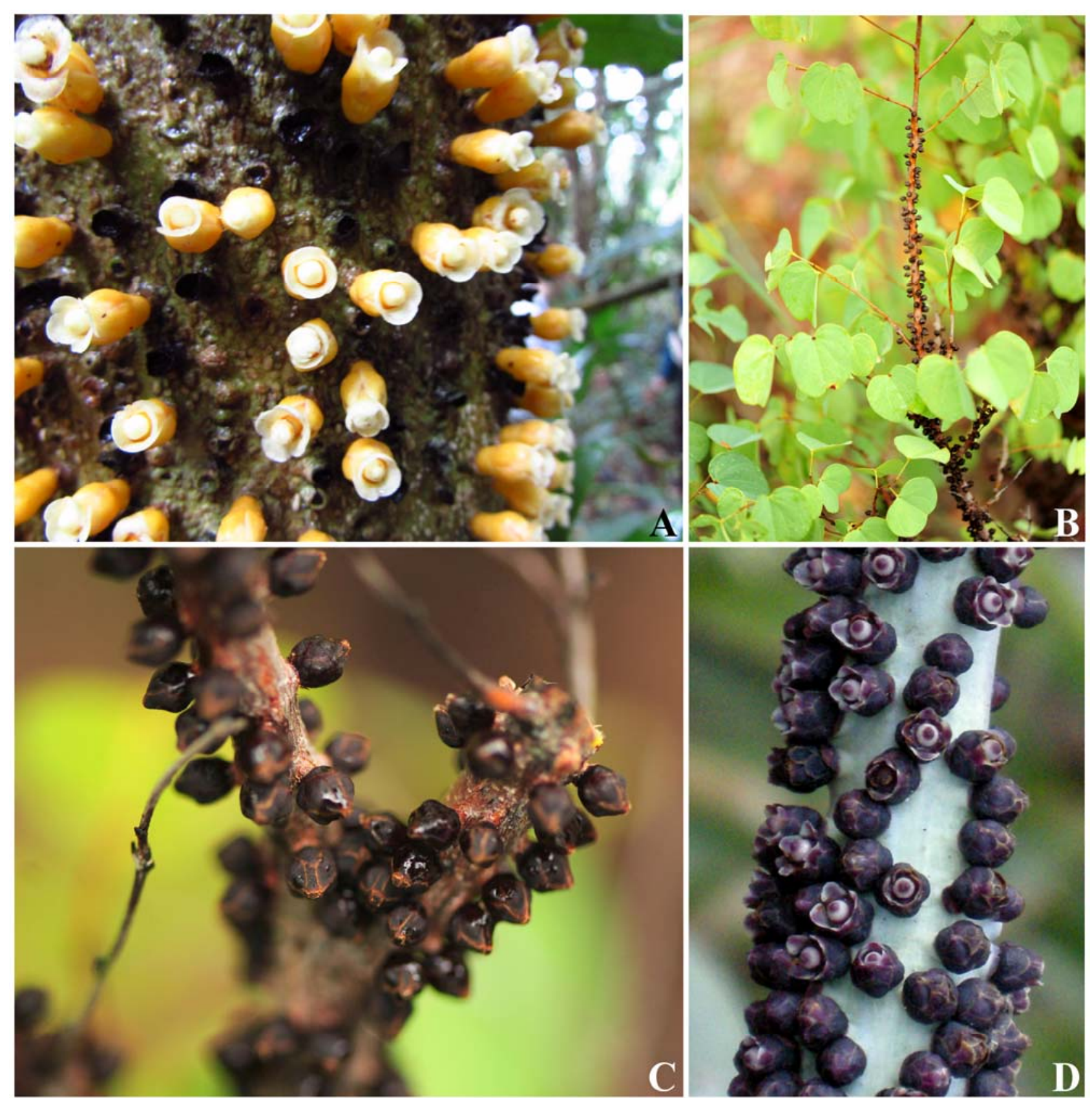

Figura 3. A. Flores de Apodanthes caseariae. B-D. Pilostyles blanchetii: B- botões florais em Bauhinia cf. pulchella (Leguminosae); C- detalhe dos botões florais; D- flores (espécime proveniente da Serra do Cipó, MG). (Fotos: A- L.C. Marinho; B, C- J.A. Siqueira Filho; D- G. Shimizu).

\section{AgRADECIMENTOS}

Os autores agradecem aos curadores dos herbários consultados, especialmente aos do HUEFS, K e NY, pelo acesso e exame às coleções; a Nicholas Hind $(K)$ e Wayt Thomas (NY), por toda a ajuda no manuseio dos espécimes, bibliografia e discussão; a José Alves Siqueira Filho e Gustavo Shimizu, pelas fotografias; à FAPESB, pelo auxílio financeiro ao Projeto Flora da Bahia (APR0162/2007), e ao CNPq, pelo apoio ao PROTAX (562278/2010-9) e ao projeto Flora da Bahia (483909/2012-2). Ao CNPq, também, pelas bolsas de Produtividade em Pesquisa concedidas a AMG (PQ
Senior), LPQ (PQ1-A) e RPO (PQ1-C), e pela bolsa de Doutorado concedida a LCM.

\section{REFERÊNCIAS}

APG III. 2009. An update of the Angiosperm Phylogeny Group classification for the orders and families of flowering plants: APG III. Botanical journal of the Linnean Society 161: 105121.

APG IV. 2016. An update of the Angiosperm Phylogeny Group classification for the orders and families of flowering plants: APG IV. Botanical Journal of the Linnean Society 181: 1-20. 
Bellot, S. \& Renner, S.S. 2014. The systematics of the worldwide endoparasite family Apodanthaceae (Cucurbitales), with a key, a map, and color photos of most species. PhytoKeys 36: 41-57.

Endriss, W. 1902. Monographie von Pilostyles ingae (Karst) (Pilostyles ulei Solms-Laub.). Flora oder Botanische Zeitung 91: 209-236.

Filipowicz, N. \& Renner, S.S. 2010. The worldwide holoparasitic Apodanthaceae confidently placed in the Cucurbitales by nuclear and mitochondrial gene trees. BMC Evolutionary Biology 10: 219-226.

Flora do Brasil 2020 (em construção). Fabaceae. In: Flora do Brasil 2020. Jardim Botânico do Rio de Janeiro. Disponível em: $<$ http://floradobrasil.jbrj.gov.br/reflora/floradobrasil/FB115>. Acesso em: 22 mar. 2019

Groppo, M. 2018. Apodanthaceae. In: Flora do Brasil 2020 (em construção). Jardim Botânico do Rio de Janeiro. Disponível em: $<$ http://floradobrasil.jbrj.gov.br/reflora/floradobrasil/FB87382>. Acesso em: 25 nov. 2018.
Groppo, M.; Amaral, M.M. \& Ceccantini, G.C.T. 2007. Flora da Serra do Cipó, Minas Gerais: Apodanthaceae (Rafflesiaceae s.l.), e notas sobre a anatomia de Pilostyles. Boletim de Botânica da Universidade de São Paulo 25: 81-86.

Harms, H. 1935. Rafflesiaceae. In: A. Engler \& K. Prantl (eds), Die Natürlichen Pflanzenfamilien. Vol. 16b. Engelmann, Leipzig, p. 243-281.

Meijer, W. 1993. Rafflesiaceae. In: K. Kubitzki, J.G. Rohwer \& V. Bittrich (eds), The Families and Genera of Vascular Plants. Vol. 2. Springer-Verlag, Berlin, p. 557-563.

Pastore, M.; Rangel, W.M. \& Giulietti, A.M. 2018. Flora das Cangas da Serra dos Carajás, Pará, Brasil: Apodanthaceae. Rodriguésia 69: 1049-1053.

Solms-Laubach, H.G. 1901. Rafflesiaceae. In: A. Engler (ed.), Das Pflanzenreich. Vol. IV.75. Engelmann, Leipzig, p. 1-19.

Vattimo, I. 1971. Contribuição ao conhecimento da tribo Apodantheae R.Br. Parte 1 - conspecto das espécies (Rafflesiaceae). Rodriguésia 26: 37-62.

\section{LISTA DE EXSICATAS}

Amorim, A.M. 2898 (2.1); Anderson, W.R. 37104 (2.1); Aona, L.Y.S. 1868, 2298 (1.1), 2898 (2.1); Blanchet, J.S. 2861 (2.1); Carvalho, A.M. 4075 (1.1), 6635 (2.1); Clark, H.D. 8358 (1.1); Conceição, S.F. 83 (2.1); França, F. 2329 , 5710 (2.1); Gardner, G. 3639 (2.1); Giulietti, A.M. PCD2280 (2.1); Harley, R.M. 24526, 26163, 28328, 53495 (2.1); Hind, N. PCD4267 (2.1); Irwin, H.S. 14617, 14911, 31508, 31545, 31560,31588 (2.1); Jardim, J.G. 2866 (2.1); Maciel, J.R. 1429 (2.1); Melo, E. 2273, 2898, 11792 (2.1); Mexia, Y. 4540 (1.1); Poitier, P.A. s/n K barcode 60131 (1.1); Prance, G. 21353 (1.1); Proctor, G.R. 48666 (2.1); Purpus, C.A. 9153 (P. mexicana); Queiroz, L.P. 13969 (2.1); Rangel, W.M. 1 (2.1); Roque, N. CFCR 14953 (2.1); Siqueira Filho, J.A. 4071 (2.1); Thomas, W.W. 11855 (1.1); Stannard, B. H51762 (2.1); Ule, E. 3094, 7078, 7079; 7161, 7895 (2.1). 